\title{
Experimental Study on a Self-Centering Earthquake-Resistant Masonry Pier with a Structural Concrete Column
}

\author{
Lijun Niu and Wenfang Zhang \\ College of Architecture and Civil Engineering, Taiyuan University of Technology, Taiyuan 030024, China \\ Correspondence should be addressed to Wenfang Zhang; zhangwenfang@tyut.edu.cn
}

Received 28 November 2016; Revised 8 March 2017; Accepted 2 April 2017; Published 25 May 2017

Academic Editor: Carlo Santulli

Copyright (c) 2017 Lijun Niu and Wenfang Zhang. This is an open access article distributed under the Creative Commons Attribution License, which permits unrestricted use, distribution, and reproduction in any medium, provided the original work is properly cited.

\begin{abstract}
This paper proposes a slotting construction strategy to avoid shear behavior of multistory masonry buildings. The aspect ratio of masonry piers increases via slotting between spandrels and piers, so that the limit state of piers under an earthquake may be altered from shear to rocking. Rocking piers with a structural concrete column (SCC) form a self-centering earthquake-resistant system. The in-plane lateral rocking behavior of masonry piers subjected to an axial force is predicted, and an experimental study is conducted on two full-scale masonry piers with an SCC, which consist of a slotting pier and an original pier. Meanwhile, a comparison of the rocking modes of masonry piers with an SCC and without an SCC was conducted in the paper. Experimental verification indicates that the slotting strategy achieves a change of failure modes from shear to rocking, and this resistant system with an SCC incorporates the self-centering and high energy dissipation properties. For the slotting pier, a lateral story drift ratio of $2.5 \%$ and a high displacement ductility of approximately 9.7 are obtained in the test, although the lateral strength decreased by $22.3 \%$ after slotting. The predicted lateral strength of the rocking pier with an SCC has a margin of error of $5.3 \%$.
\end{abstract}

\section{Introduction}

Multistory unreinforced masonry (URM) buildings have been used extensively in the last several decades, and a large number of these buildings are still being erected at moderate cost during the process of urbanization in China. These structures have many advantages, but their performances during earthquakes are not satisfactory, such as in the Tangshan earthquake of 1976 [1]. After this earthquake, which led to the collapse of a vast number of URM buildings, an important innovation for the seismic protection of multistory URM structures is the addition of SCC. For a masonry structure with SCC, the masonry walls are the dominating lateral force-resisting elements, and, unlike confined masonry construction, the strength of masonry confined by SCC would not increase when used in seismic calculation. SCC is not involved in the seismic calculation of walls in most cases, which only belong to details of seismic design in existing Chinese code for seismic design of buildings. The location of SCC should be determined according to seismic fortification intensity and number of floors. Figure 1 provides several photographs of construction of SCC and masonry walls containing SCC and ring beam. The concrete of SCC would be poured after masonry of one story completed. SCC connect with masonry part by horizontal reinforcements, as shown in Figure 1(b). The vertical interval of horizontal reinforcements is usually $500 \mathrm{~mm}$, and more details about horizontal reinforcements might be observed from design details of experimental specimens, which are shown in Figure 7. The longitudinal reinforcement ratio of SCC is low, and the largest ratio is just over 1.0\% [2]. In general, SCC is a primary structural configuration in seismic design of masonry buildings in China, and masonry structures with SCC are still considered as URM systems owing to the low reinforcement ratio and small section of SCC [3].

Observation of seismic damage to URM piers, as well as laboratory experimental tests, showed that masonry piers subjected to in-plane loading may exhibit two typical types of behavior: flexural and shear deformations, and corresponding possible failure modes appear such as rocking, diagonal tension, diagonal stepped cracking, toe compression, and bed-joint sliding [4-6]. Previous research has revealed that 


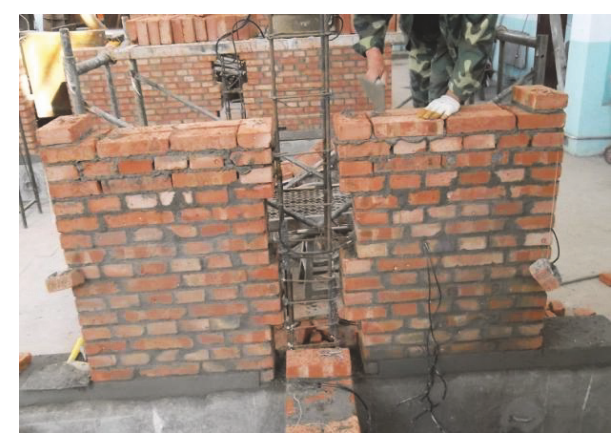

(a)

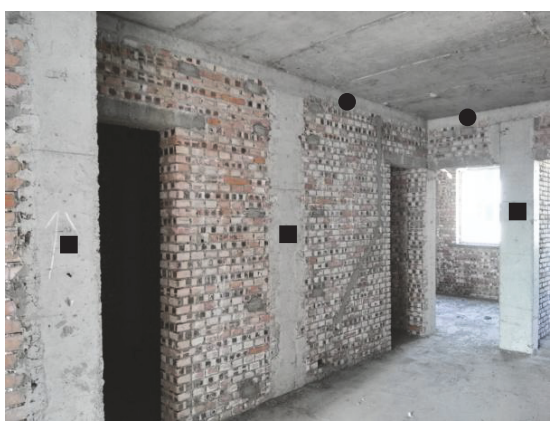

(c)

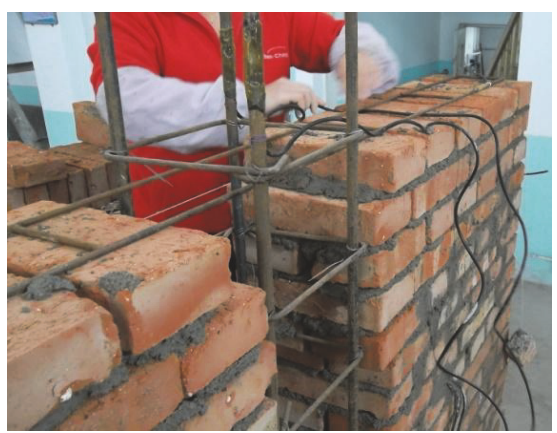

(b)

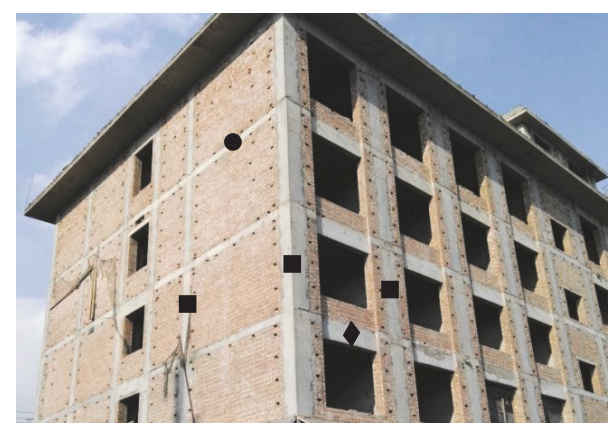

(d)

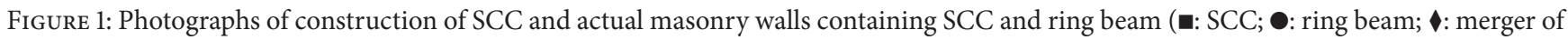
ring and lintel beam).

the occurrence of different failure modes depends on several parameters: the geometry of the pier; the boundary conditions; the acting axial load; and the mechanical characteristics of the masonry constituents (mortar, blocks, and interfaces). The height-to-length aspect ratio of the geometry has a significant influence on the failure mode of masonry walls under seismic action in the above respects. The paper proposes a slotting construction strategy which aims to increase the aspect ratio of masonry walls. For walls with window openings, they might be slotted between spandrels and piers, so that the limit state piers under an earthquake may be altered from brittle shear to ductile rocking. More details about the slotting strategy are shown in Section 2.

The rocking mode is an expected mode owing to its selfcentering behavior in a lateral loading. The notion of selfcentering stemmed from the rocking idea was applied in the design of the rail bridge at first [7]. In order to improve the lateral capability of a rocking unreinforced wall under inplane seismic loading, unbonded prestressed technology has been incorporated in masonry walls to provide self-centering behavior $[8,9]$. Unbonded prestressed tendons were applied in the center of a concrete wall or a masonry wall in some tests, such as tests conducted by Restrepo et al. [10-12]. Several schematic diagrams and some simple information of these tests are shown in Figures 2(a)-2(c). Rocking walls in these tests showed a high strength capability, and an Sshaped global hysteresis loop was generally obtained. Stanton proposed a rocking construction method of a long concrete wall with prestressed technology, as shown in Figure 2(d) [13].
If rocking walls contain special energy dissipators, such as those shown in Figures 2(e) and 2(f), then a full hysteresis loop would be obtained [10].

In recent years, several tests on strengthening URM buildings using external prestressed technique were also conducted in China [14-16]. Figure 3 shows several experimental pictures, and these experimental piers generally showed a shear behavior owing to the low aspect ratio and the high compressive stress of piers.

For masonry piers containing an SCC, the SCC is generally located at the center of section, and the location is similar to that of prestressed tendons in Figure 2. Unlike the above existing researches about rocking wall, for rocking masonry piers with an SCC formed by slotting, it is the conventional reinforcements instead of prestressed tendons in the center of walls. The self-centering earthquake-resistant system is expected to recenter subjected to the relatively, moderate earthquakes and show plastic behavior subjected to the strong earthquakes owing to the low strength of longitudinal reinforcements. The shear mode of URM piers is the only failure mode, and the rocking mode of piers, especially piers with an SCC, is not presented in existing Chinese code for seismic design of buildings [3]. The primary aim of the paper is to conduct seismic performance evaluation of rocking masonry piers with an SCC.

The first part of this paper presents briefly a slotting strategy for Chinese multistory masonry buildings to avoid shear failure. The rocking strength equations of masonry piers with an SCC are presented in the second part. Meanwhile, in order 


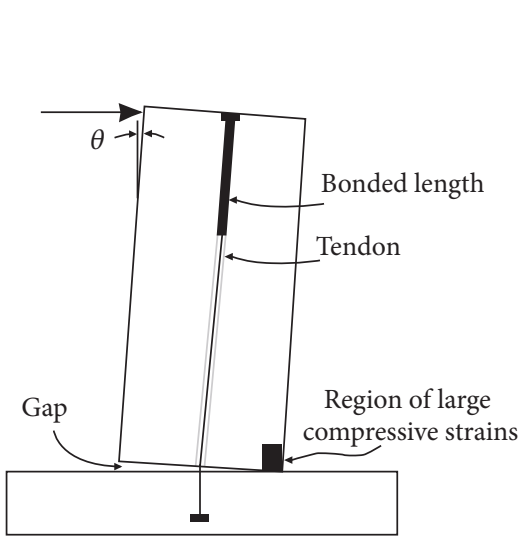

(a) Precast concrete wall [10]

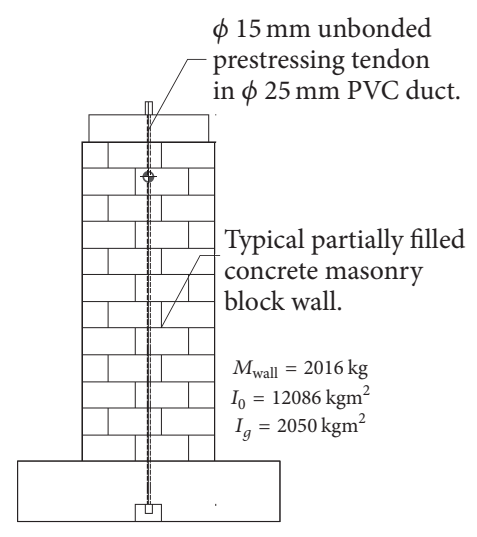

(b) Concrete hollow block wall [11]
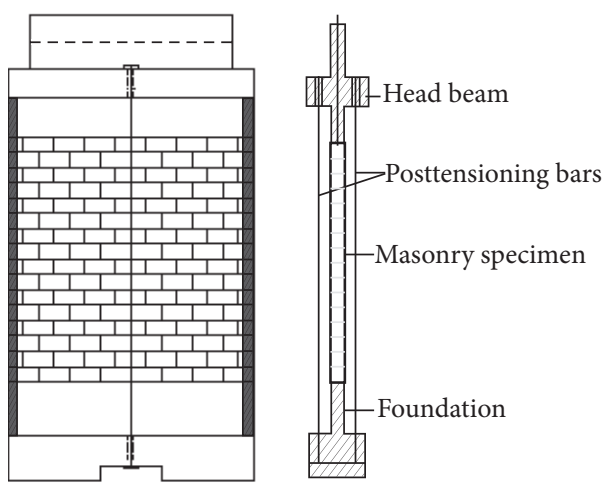

(c) Solid brick wall with extra prestressing [12]

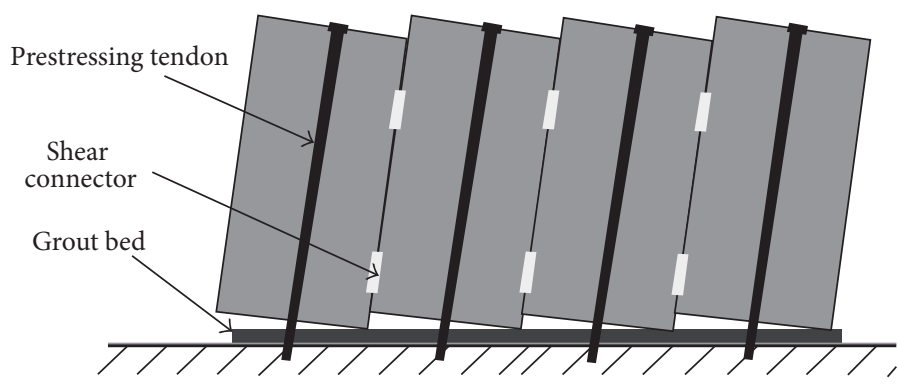

(d) Rocking strategy on a long concrete wall [13]

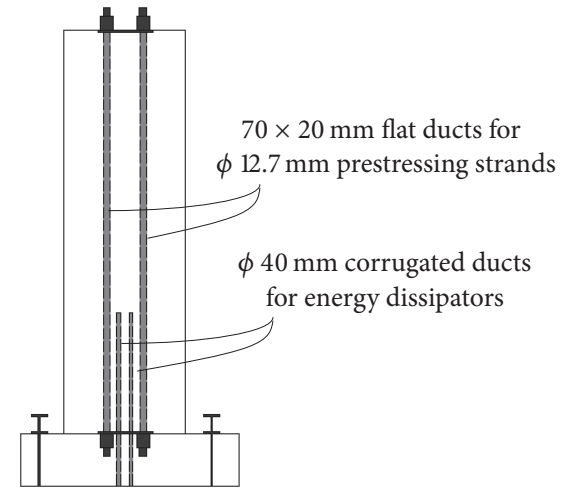

(e) Concrete wall with energy dissipators [10]

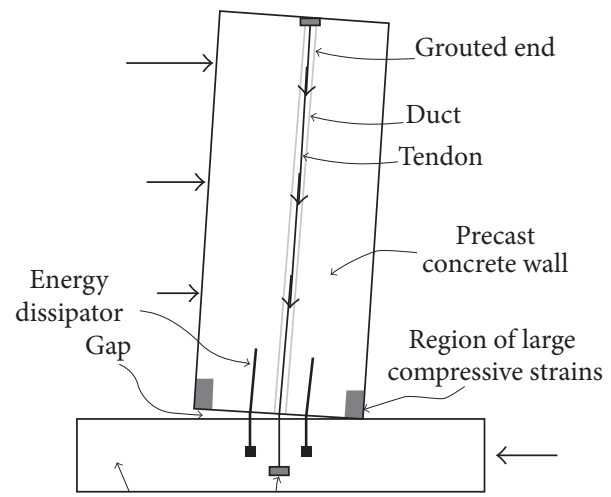

(f) Precast concrete wall with energy dissipators [10]

FIGURE 2: Existing tests and strategy of rocking walls with prestressed tendon.

to predict the displacement ductility of rocking masonry piers, existing equations are also given in this part. In the last part, pseudo-static tests of two full-scale masonry piers, with or without slotting, and with an SCC, were conducted, and the equations given in the second part would be validated with the test results.

\section{Slotting Strategy of Rocking Masonry Buildings}

Figure 4 illustrates a slotting strategy to avoid shear behavior of multistory masonry buildings. The strategy presented might be applied in construction of new buildings. A masonry building could be divided into two seismic zone at the $1 / 3$ height of buildings, the stories above the $1 / 3$ height belong to ordinary seismic zone, and the other stories belong to key seismic zone. Slots used to increase the aspect ratio of walls are applied in key seismic zone. For walls with window openings, slots might be set between piers and spandrels, and soft materials are filled inside the slots. Above window openings, adopting either slots above the lintel beam or merger of ring and lintel beam might be determined by the height of the lintel wall. After slotting, stability of cantilever spandrels constrained by circumjacent reinforced concrete belts can 


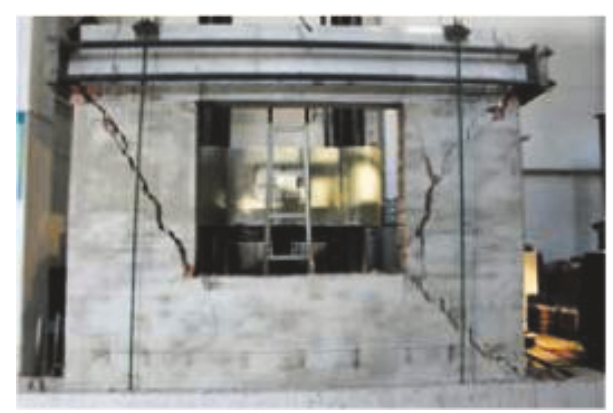

(a) Wall with opening [14]

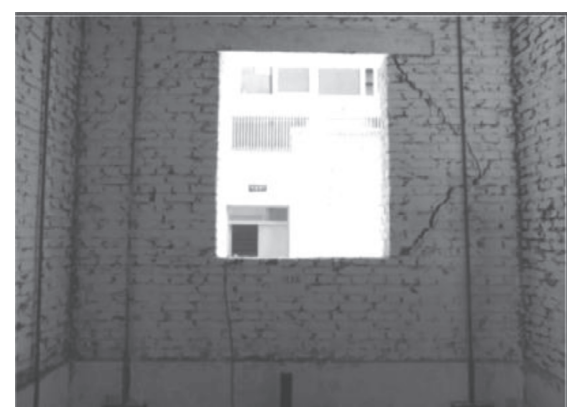

(b) Two-story building [15]

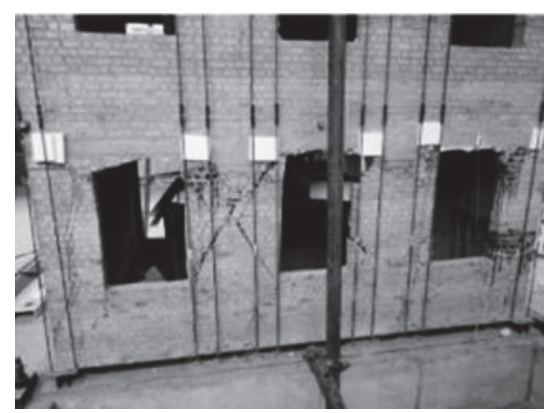

(c) Four-story building [16]

FIGURE 3: Photographs of masonry structures reinforced with external prestressed tendons in China.

be ensured. The stories which belong to ordinary seismic zone might be constructed as ordinary treatments, and those belonging to key seismic zone would be constructed by using strong details of seismic design.

\section{In-Plane Rocking Behaviors of Masonry Walls}

3.1. Rocking Strength of URM Piers. Two possible types of in-plane damage can occur with rocking mode: rocking and rocking/toe crushing. For the rocking mode of URM piers, if the tensile strength of masonry is neglected, then the lateral strength $V_{r}$ may be determined using (1) based on FEMA 306 (1999) and FEMA 273 (1997) [17, 18].

$$
V_{r}=0.9 \alpha P_{\mathrm{CE}}\left(\frac{L}{h_{\mathrm{eff}}}\right),
$$

where $\alpha$ is factor equal to 0.5 for a fixed-free cantilever wall or equal to 1.0 for a fixed-fixed pier, $P_{\mathrm{CE}}$ is expected vertical axial compressive force per load combination in FEMA 273, $L$ is length of the wall, and $h_{\text {eff }}$ is effective height of the pier. The parameter $h_{\text {eff }}$ may be varied to reflect the observed crack patterns.

Flexural compressive stress in the compressive toe is assumed to be distributed across an equivalent rectangular stress block in rocking/toe crushing mode [19]. If the clamping force created at the corners is defined as a parameter $P_{u}$, then

$$
P_{u}=\kappa t l_{c} f_{\mathrm{me}},
$$

where $\kappa$ is compressive strength reduction factor (a common assumption is an equivalent rectangular stress block with $\kappa=0.85), t$ is thickness of masonry walls, $l_{c}$ is depth from the neutral axis to the fiber of maximum compressive strain, and $f_{\mathrm{me}}$ is expected compressive strength of the masonry.

Equation (3) gives the lateral strength $V_{\mathrm{tc}}$ for rocking/toe crushing mode presented in FEMA 273, and a similar expression is also presented by Magenes and Calvi [20].

$$
V_{\mathrm{tc}}=\alpha P_{\mathrm{CE}}\left(\frac{L}{h_{\mathrm{eff}}}\right)\left(1-\frac{f_{\mathrm{ae}}}{0.7 f_{\mathrm{me}}}\right),
$$

where $f_{\text {ae }}$ is expected vertical axial compressive stress as defined in FEMA 273.

3.2. Rocking/Toe Crushing Strength for Masonry Piers with an SCC. Rocking behavior in piers with an SCC would be more likely to result in toe crushing upon repeated cycles, because higher drift levels are expected. Ignoring the tension capacity of masonry and concrete, based on compression theory with large eccentricity, the mechanical model of rocking masonry piers with an SCC is shown in Figure 5, and equations of the peak lateral strength are expressed as

$$
\begin{aligned}
V_{\mathrm{tcc}} & =\frac{M_{u}}{h_{\mathrm{eff}}} \\
M_{u} & =M_{e}+P_{\mathrm{CE}} \cdot\left(l_{\mathrm{tm}}+\frac{b}{2}\right) \\
M_{e} & =f_{y} A_{\mathrm{as}}\left(l_{\mathrm{tm}}+\frac{b}{2}\right)+l_{\mathrm{cm}} P_{u}(1-0.5 \kappa) \\
l_{\mathrm{cm}} & =\frac{\left(P_{\mathrm{CE}}+f_{y} A_{\mathrm{as}}\right)}{\kappa t f_{\mathrm{me}}}
\end{aligned}
$$




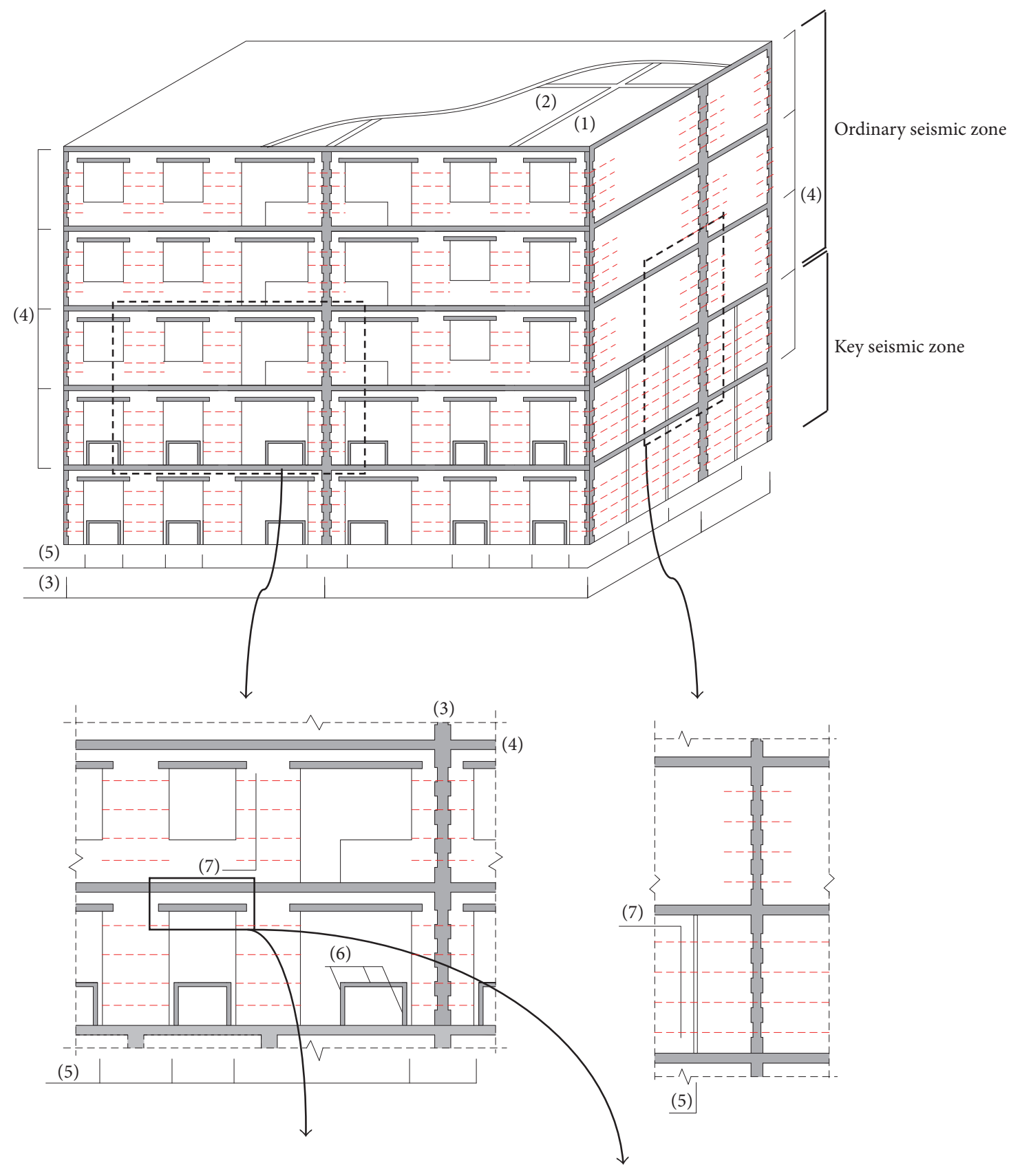

(4)

(5)

(9)

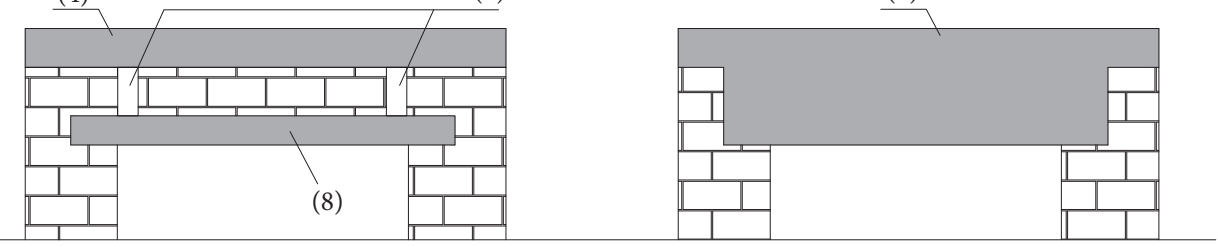
(1) Cross wall
(6) Reinforced concrete belts
(2) Longitudinal wall
(7) Horizontal reinforcements
(3) SCC
(8) Lintel beam
(4) Ring beam
(9) Merger of ring and lintel beam

(5) Slots

FIGURE 4: Construction strategy of rocking multistory masonry buildings. 


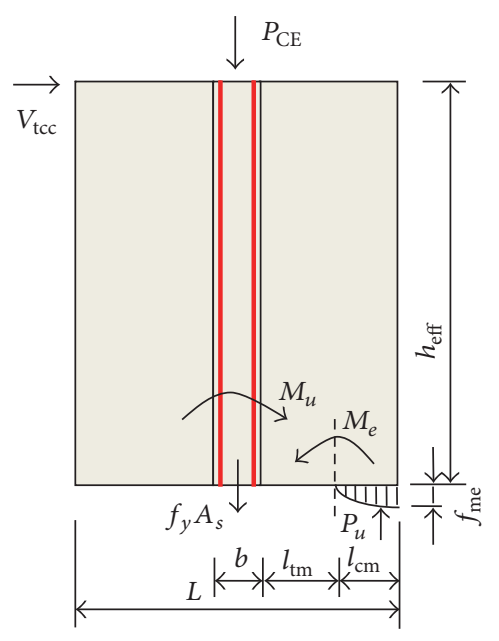

FIGURE 5: Mechanical model of rocking masonry walls with an SCC.

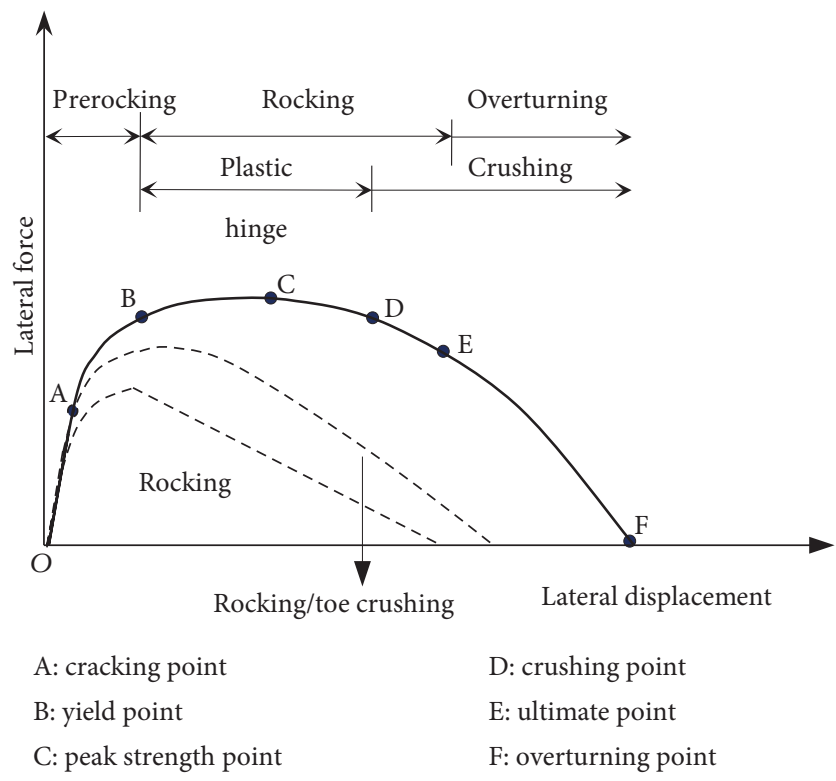

FIGURE 6: Excepted lateral force-displacement of rocking masonry piers.

where $V_{\text {tcc }}$ is expected rocking strength of piers with an SCC, $M_{u}$ is bending strength based on compression theory with large eccentricity, $M_{e}$ is is defined about the "stress axis," $l_{\mathrm{cm}}$ is depth of compression zone at the peak strength, $l_{\mathrm{tm}}$ is depth from the neutral axis to the side of SCC at the peak strength, $b$ is width of the SCC, $f_{y}$ is expected yield strength of reinforcements, and $A_{\text {as }}$ is area of all longitudinal reinforcements.

\subsection{Expected Force/Displacement Relationships for Rocking} Behavior. Several models have been proposed to predict the force-displacement response of URM walls with a dominant rocking mode [21, 22]. Figure 6 indicates expected lateral force-displacement relationships of rocking masonry walls, and the solid curve represents that of piers with an SCC; the dashed curves represent that of piers without an SCC. Several expected critical points in the solid curve are also indicated in Figure 6 . The yield point means that the strain on longitudinal reinforcements at cracks just reaches the yield strain, and the ultimate point represents that the residuary lateral strength is equal to $85 \%$ of the peak strength. It is expected that significant strength degradation would not occur during a large deformation from the yield point to toe crushing point.

For rocking piers with an SCC, displacements may be predicated through a concentrated plastic hinge model, and a plastic hinge/rigid plane model is considered as the calculation diagram. The plastic hinge in masonry is not a point per se; it is a zone exceeding the yield curvature at large displacements. For a vertical cantilever masonry wall with an SCC, the equivalent plastic hinge length may be estimated from the following equation [18]:

$$
l_{p}=0.2 L+0.04 h_{e}
$$

where $l_{p}$ is equivalent plastic hinge length and $h_{e}$ is height to the resultant of the lateral force.

Paulay and Priestley provide a simple model for calculating the yield displacement [23], which is

$$
\Delta_{y}=\frac{\phi_{y} H^{2}}{3}
$$

where $\phi_{y}$ is the yield curvature of a masonry section and $H$ is the shear height of masonry walls.

The yield curvature $\phi_{y}$ may be calculated as

$$
\phi_{y}=\frac{\varepsilon_{y}}{\left(L / 2-l_{\mathrm{cy}}\right)},
$$

where $\varepsilon_{y}=f_{y} / E_{s}$ and $l_{c y}$ is the neutral-axis depth at yield curvature and $E_{s}$ is the elastic modulus of steel.

If a rocking pier with an SCC is idealized as a cantilever element with a zone of concentrated plastic rotation at the base, then the ultimate displacement capacity at the top of walls is

$$
\Delta_{p}=\left(\phi_{m}-\phi_{y}\right) h_{\mathrm{eff}},
$$

where $\phi_{m}$ is the maximum curvature of a masonry section and $h_{\text {eff }}=H-0.5 l_{p}$.

The maximum curvature of a section is controlled by the maximum compression strain at the extreme fiber, since steel strain ductility capacity is typically high. The maximum curvature $\phi_{m}$ may be expressed as

$$
\phi_{m}=\frac{\varepsilon_{\mathrm{cm}}}{l_{\mathrm{cu}}},
$$

where $\varepsilon_{\mathrm{cm}}$ is the maximum compression strain of masonry material and $l_{\mathrm{cu}}$ is the neutral-axis depth at ultimate curvature.

The displacement ductility can be defined as

$$
u_{\Delta}=\frac{\Delta_{p}}{\Delta_{y}} .
$$



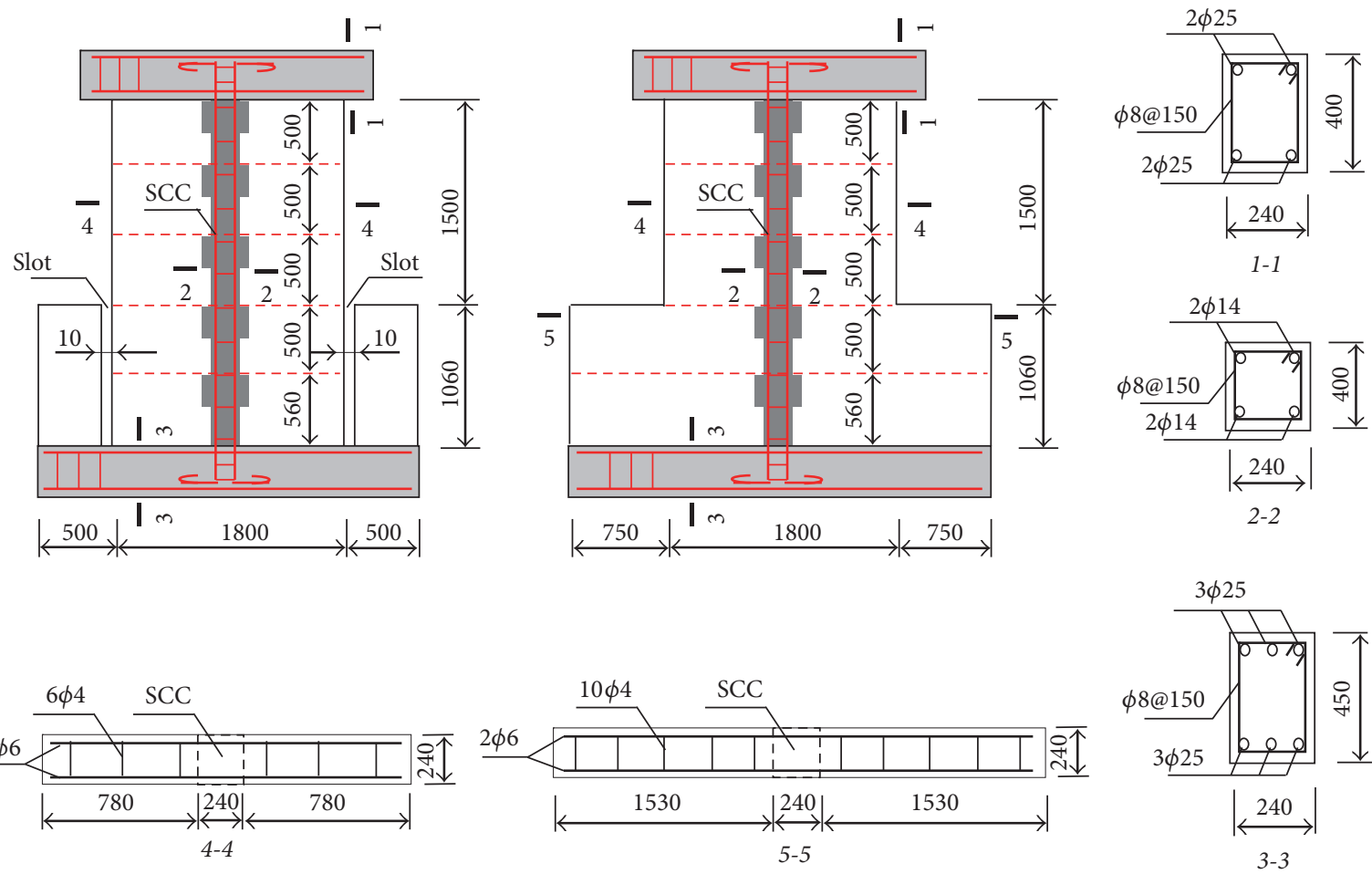

Figure 7: Details of specimens (mm).

The minimum demand of the width of slots should be determined based on the predicted ultimate displacement, and it is

$$
d_{s}=\frac{h_{s}-0.5 l_{p}}{h_{\mathrm{eff}}} u_{\Delta},
$$

where $d_{s}$ is the minimum demand of the width of slots and $h_{s}$ is the height of spandrels.

\section{Experimental Test of Masonry Walls with an SCC}

4.1. Design of Specimens. Design details of both specimens are shown in Figure 7. Two full-scale masonry walls denoted as 1TB2 and 1TS2, respectively, had the same configuration; only one distinction between these two walls was that the specimen 1TB2 containing slots was expected to show a rocking failure, while the specimen 1TS2 without slots was expected to show a prevalent shear failure. Both specimens consisted of a reinforced concrete footing, a top beam, and a brick wall with an SCC. The geometry of walls was adopted in accordance with common constructions in China. Piers were $2560 \mathrm{~mm}$ high (clear height), $1800 \mathrm{~mm}$ wide, and $240 \mathrm{~mm}$ thick, and spandrels were $1000 \mathrm{~mm}$ high. The aspect ratio of specimen 1TB2 was 1.73 and that of the specimen 1TS2's pier was 0.87 . It is particularly worth pointing out that the slotting width of specimen 1TB2 was $10 \mathrm{~mm}$ and hollow carton boards were applied to fill slots. Masonry walls were constructed from solid clay-bricks $(240 \times 115 \times 53 \mathrm{~mm})$ and mortar. The thickness of joints was $10 \mathrm{~mm}$. Longitudinal reinforcements inside the SCC were $4 \phi 14$, and the reinforcement ratio was $0.14 \%$. The other details of walls were designed in accordance with the corresponding Chinese codes.

4.2. Material Properties. The designed strength grades of all materials such as brick, mortar, concrete, and reinforcements were selected in accordance with the prevailing values in fact. Samples of plain round bars were subjected to tensile testing and the original gage length of $\phi 14$ bars, and $L_{o}$ calculated by (15) was $70 \mathrm{~mm}$.

$$
L_{o}=5.65 \sqrt{A_{s}}
$$

where $A_{s}$ is the area of one longitudinal reinforcement. The average yield strengths for the $\phi 6$ and $\phi 14$ reinforcements were $342.1 \mathrm{MPa}$ and $293.1 \mathrm{MPa}$, respectively. Because the strength yield ratio of $\phi 14$ bars was 1.49 and the percentage elongation after fracture was 38.5\%, the bars have a high ductility capacity. Also, the average compressive strengths measured for the brick unit and the concrete of the SCC were 15.1 $\mathrm{MPa}$ and $35.3 \mathrm{MPa}$, respectively. The mixing ratio of the mortar after trial batches was 0.5:2:9 (cement : lime : sand), and the average compressive strength of the mortar measured from nine cubic samples was $17.1 \mathrm{MPa}$. The compressive strength of masonry estimated according to the strengths of brick and mortar was $6.76 \mathrm{MPa}$.

4.3. Test Setup. The test setup, which is shown in Figure 8, primarily consisted of a reacting-force wall providing horizontal supports and a reaction frame providing vertical supports. Constant vertical pressure was applied using a $500 \mathrm{kN}$ jack. 


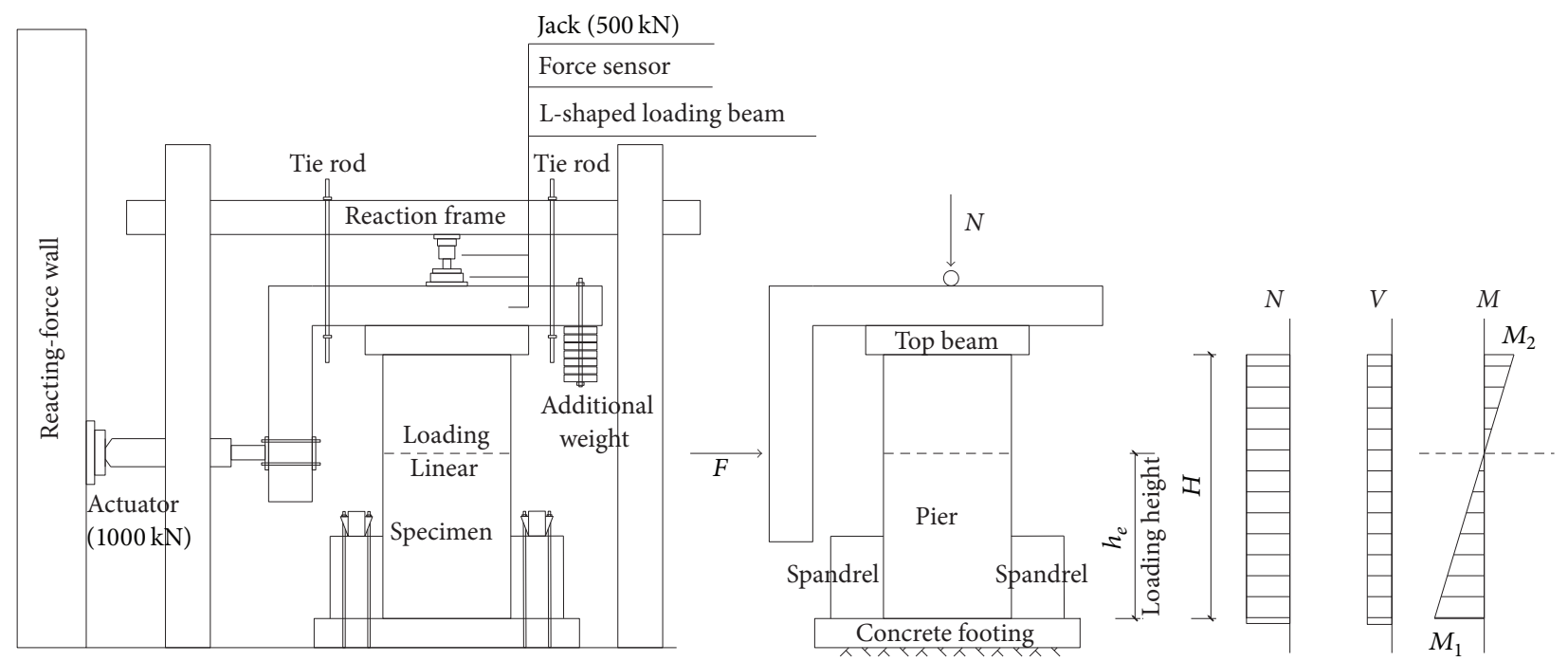

FIGURE 8: Equipment figure and the internal force diagram of specimens.

The vertical loading, which included additional weight, was $132 \mathrm{kN}$, and the corresponding average compressive stress was $0.3 \mathrm{MPa}$. Pseudo-static tests were performed by a horizontal hydraulic actuator $(1000 \mathrm{kN})$ providing a lateral force to a welded-steel L-shaped loading beam with an I-shaped cross section, and a contraflexure point would be formed on the wall by using the L-shaped loading beam. Under this loading pattern, the interior force of specimens in elastic stage is also shown in Figure 8 . The loading beam was safeguarded by two vertical tie rods hinged to the reaction frame. A vertical height from the top of concrete footing to the lateral loading resultant was defined as the loading height. The loading height was the same height as the contraflexure point on the wall and it was equal to $1830 \mathrm{~mm}$ in the test, which was located at approximately two-thirds of one-story height.

4.4. Instrumentation. Figures 9 and 10 schematically show the test instrumentation. Observations of walls mainly included in-plane deformations; strains of steel bars, which included longitudinal reinforcements inside the SCC and horizontal reinforcements inside masonry; the pattern of cracks; and measurement of loading forces. Distances of strain gages are marked in Figure 10, and the vertical direction means the data at longitudinal reinforcements and the horizontal direction means the data at horizontal reinforcements. One face of walls was used to monitor the creation and progression of cracks, whereas the other face was used to install external instrumentation. Vertical loading was verified by a load cell positioned in series with the vertical jack, and verification of the lateral force was achieved by using a strain gage at the corner of the L-shaped loading beam, because the strain is approximately proportional to the lateral force.

4.5. Loading History. The test specimens were subjected to cyclic lateral loading under constant vertical axial load, and the loading histories are shown in Figure 11, which consisted of force-controlled stages and displacement-controlled stages. Solid curves represent force-controlled mode and dashed curves represent displacement-controlled stages in Figure 11. Note that the displacements in Figure 11 represent data produced by the hydraulic actuator, not the displacements on the top of walls read by equipment. Therefore, the actual magnitudes of displacement are estimated.

\subsection{Experimental Results}

\subsubsection{Cracking and Failure Procedure}

1TS2. Flexural cracks first appeared at the corner of the window opening when the lateral force was equal to $70 \mathrm{kN}$, and the propagating direction was diagonally downward. These flexural cracks only followed the joints. The first flexural cracks were observed to open and close subjected to the cyclic loading. When the lateral loading is equal to $220 \mathrm{kN}$, which is near the peak lateral loading, the diagonal shear cracks initiated near the center of the pier and propagate outward. Appearing of shear cracks indicated the transfer from the bending behavior to the shear behavior. Diagonal shear cracking caused by the principal tensile stresses occurred in the units as well as the joints. Test terminated after the diagonal tension cracks significantly widened and longitudinal reinforcements were engaged. The specimen 1TS2 exhibited a typical flexural cracking/diagonal tension failure mode, as shown in Figure 12, and may be considered as the shear failure wall.

1TB2. After applying an axial force, no visible cracks were observed in the pier. The first flexural cracks appeared below the first row of horizontal reinforcements when the lateral force was equal to $60 \mathrm{kN}$. Then, these cracks propagated in level and inclined directions after an increase in the lateral loading, and slight rocking was observed during the loading cycle. Note that flexural tension cracking does not cause any damage to the entire wall. It was observed that the width of slots with filler material was insufficient for deformation of the pier. If this did not widen the slots, transfer from bending 


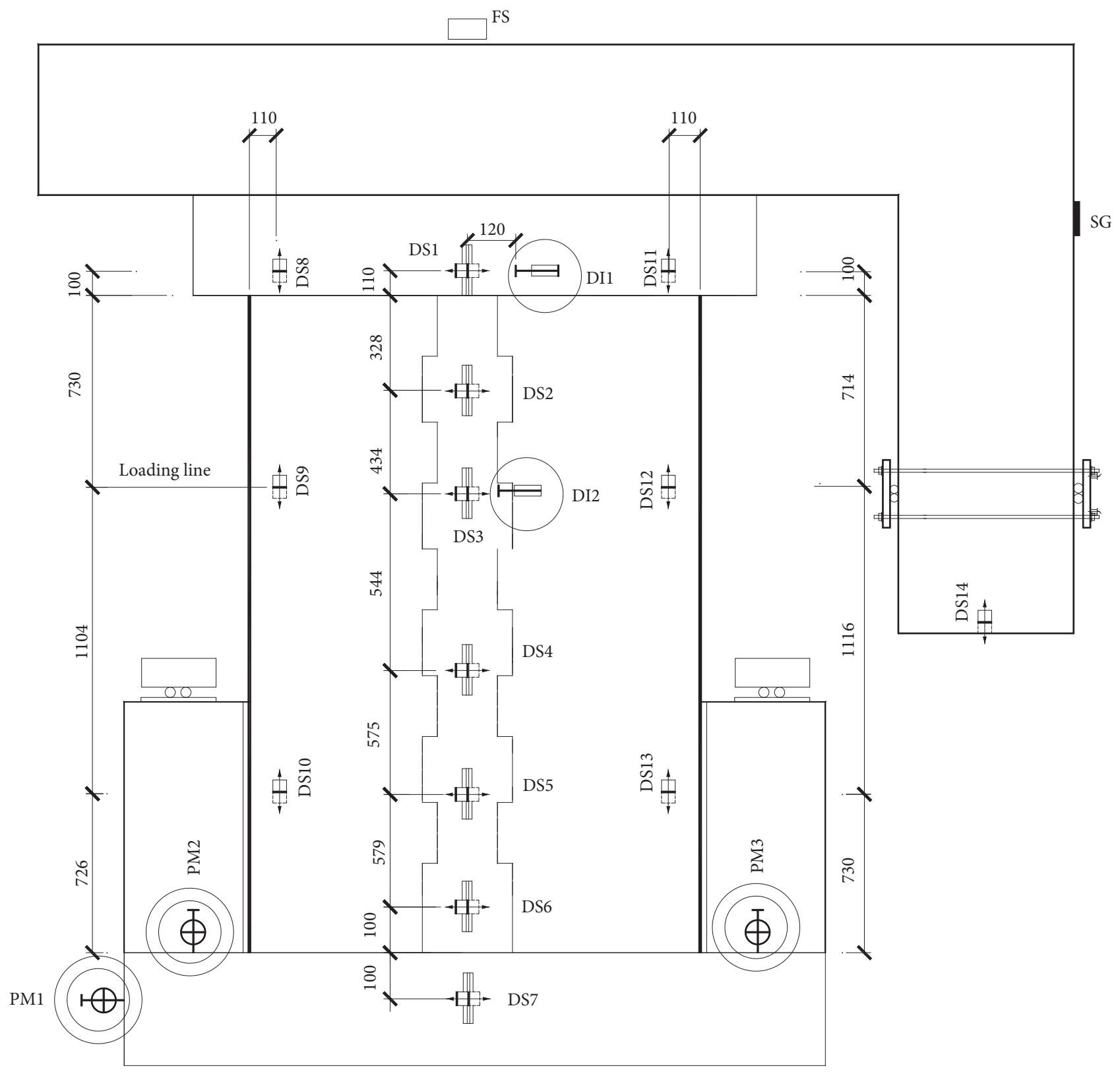

DI: linear variable differential transformer (LVDT)

DS: strain-type displacement transducer

FS: force sensors

PM: dial indicators

SG: strain gage at the corner of the L-shaped loading beam

FIgURE 9: External instrumentation.

behavior to shear behavior would occur as that appearing on the specimen 1TS2. Therefore, the slots were widened by taking down the part of the spandrels. With an increase in the lateral loading, flexural cracks also initiated at the base of the pier and propagated through the cross-section of the SCC. The phenomenon in this phase observed was that the upper four-fifths of the pier, as a rigid plane, exhibited rocking motion around the bottom of the SCC in the lateral loading cycle, and flexural cracks were observed to open and close. A stable rocking mechanism with a large deformation was established. The lateral loading arrived at the peak value before the toes cracked in the vertical direction, and then the inclined compressive cracks were also observed above the first row of horizontal reinforcements. The distribution 


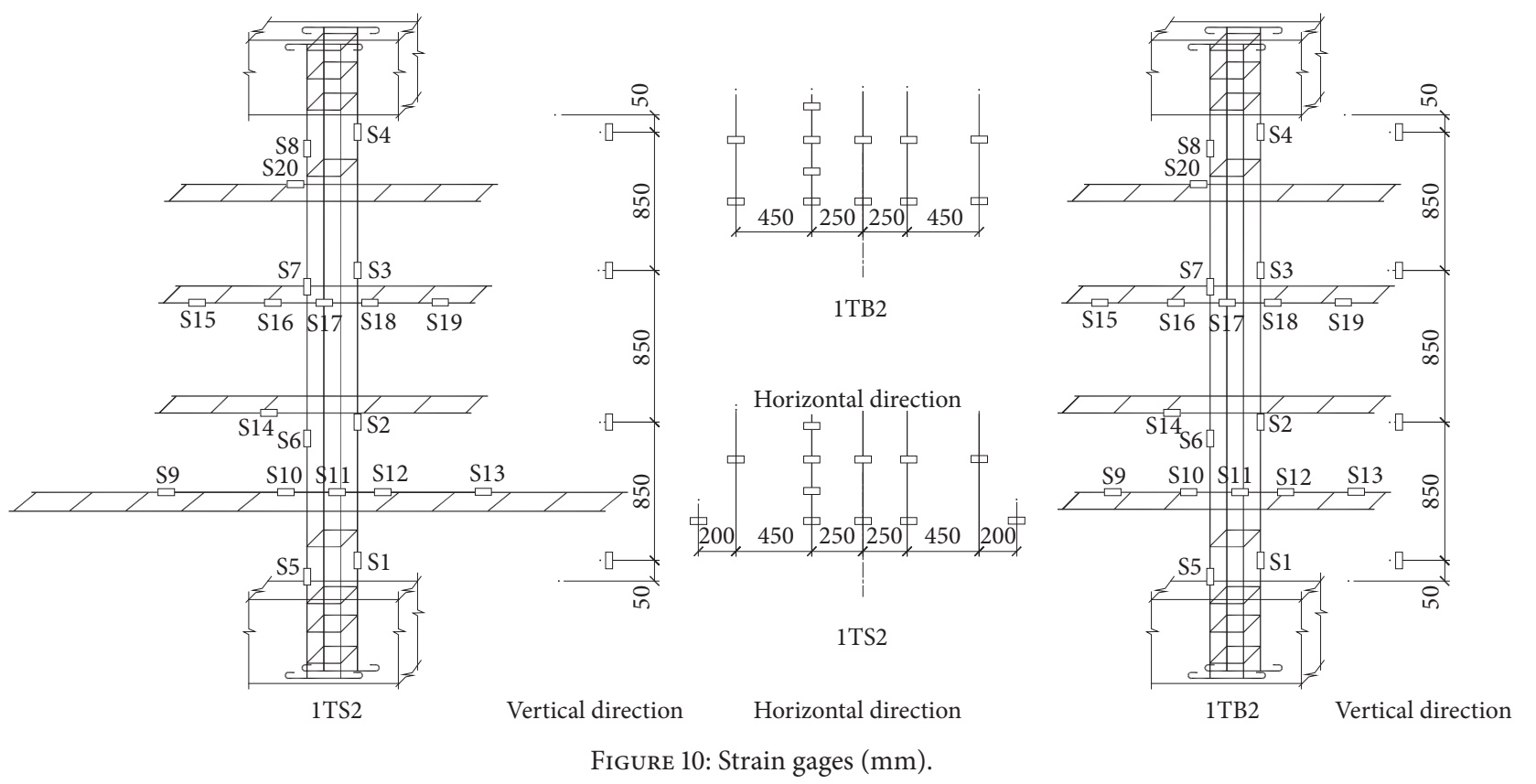

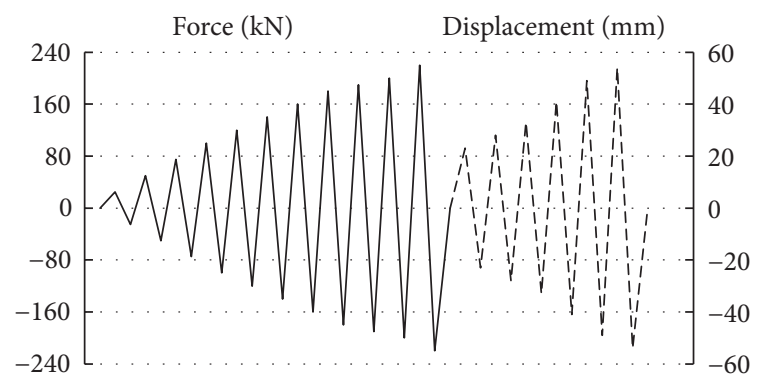

(a) $1 \mathrm{TS} 2$

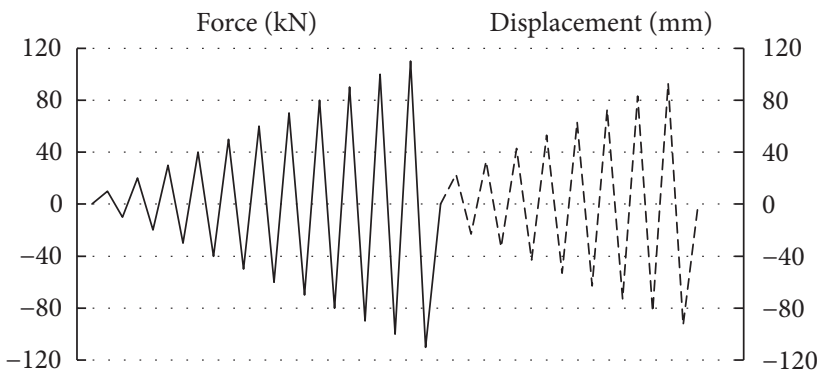

(b) $1 \mathrm{~TB} 2$

FIGURE 11: Loading history of test specimens.

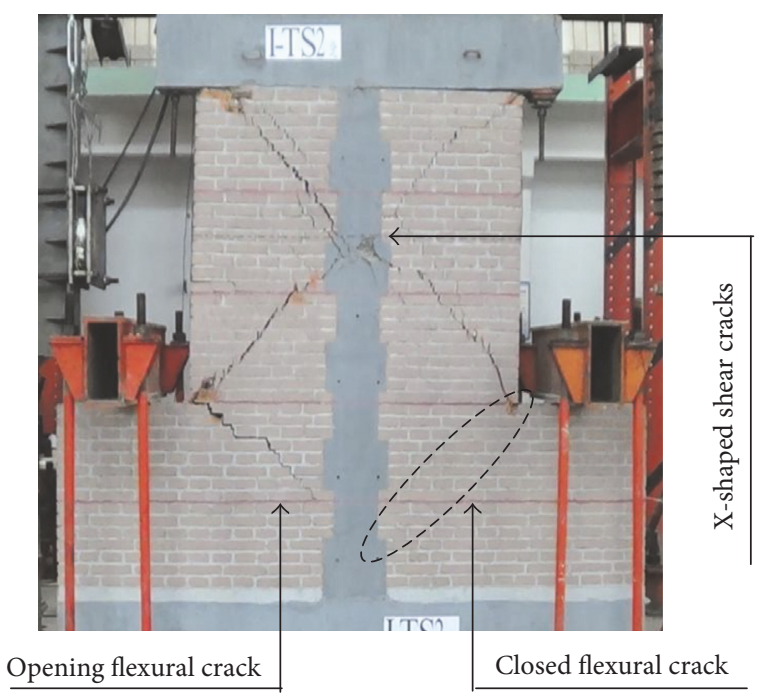

FIGURE 12: Failure photographs of the specimen 1TS2. of cracks indicates that the horizontal reinforcements inside masonry have a direct influence on the propagation of compressive cracks. After the peak strength, the toes were crushed gradually and some bricks were crushed to powder. The failure photograph of specimen 1TB2 is shown in Figure 13(a), and Figure 13(b) shows the pattern of cracks and illustrates the behavior observed during the test. The specimen 1TB2 exhibited a typical rocking/toe crushing failure mode.

In tests, both specimens firstly showed the flexural cracks; however, different failure modes ultimately occurred owing to various aspect ratios. Experimental research confirms that the slotting strategy which is used to develop a rocking failure mode is feasible. Particularly note that the sufficient width of slots and enough soft filler materials are critical factors for the transfer; if not, first flexural cracking also might transfer to the shear behavior.

4.6.2. Self-Centering Behavior and Energy Dissipation. A comparison was made by employing the benchmark test 


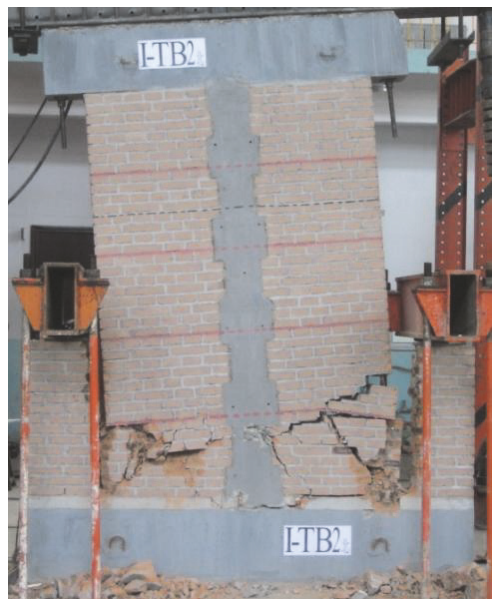

(a) Failure photograph

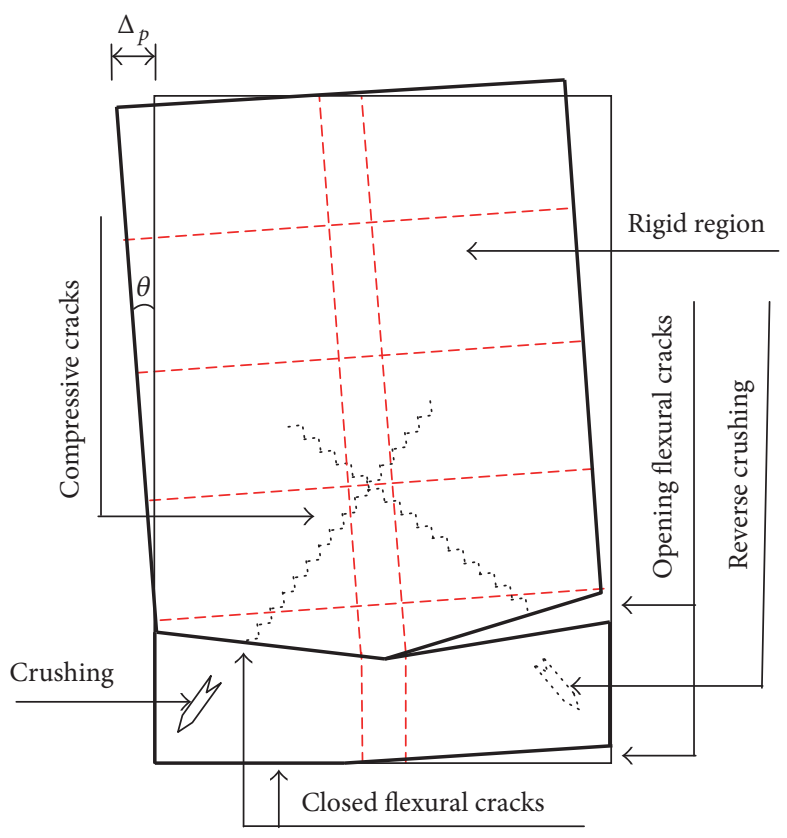

(b) A stable rocking mechanism

FIGURE 13: Failure photograph and the rocking mechanism of specimen 1TB2.

developed by Anthoine et al. [24], which utilizes two URM piers characterized by different aspect ratios. These two walls, with a width of $1000 \mathrm{~mm}$ and a thickness of $250 \mathrm{~mm}$, were made from typical Italian bricks $(55 \times 120 \times 250 \mathrm{~mm})$ arranged in English bond with mortar joints of a thickness of $10 \mathrm{~mm}$. Rotation of the horizontal edges of the walls was prevented and a cyclic displacement loading of increasing amplitude was applied to the upper side, while a constant vertical load of $150 \mathrm{kN}$ was applied in order to produce a mean compressive stress of $0.6 \mathrm{MPa}$. In this paper, a wall with an aspect ratio equal to 2.0 was used for comparison, and the corresponding experimental S-shaped global hysteresis loop is shown in Figure 14(a). Similar S-shaped curves for rocking behavior of URM piers could be provided by other tests such as those conducted by Calvi et al. [25, 26]. Besides, the entire hysteresis curve obtained in the test is shown in Figure 14(c); Figure 14(b) also shows the early hysteresis curve in order to better understand the hysteretic behavior of specimen 1TB2. The typical S-shape with the self-centering and almost nonlinear elastic property, which can be observed in Figure 14(b), is similar to that observed in Figure 14(a), owing to their typical rocking response with a little residual displacement. For the case in Figure 14(a), if no other failure mechanism occurs, the displacements can be limited only by a decrease in strength owing to second-order effects associated with overturning, whereas the dissipating energy of the URM wall would not significantly increase.

Unlike URM piers without an SCC, the latter hysteresis curve of specimen 1TB2 exhibited a significant dissipated energy capability. Negligible degradation in strength and a little slip at the wall base which is limited by a clamping force along the wall base can be observed in subsequent cycles.
The amount of dissipated energy is essentially proportional to the area of the hysteresis loops shown when the imposed displacements are large enough to induce a significant nonlinear response. A schematic of a dissipative coefficient, $E$, is shown in Figure 15(a), and the many sequences of specimen 1TB2 are also shown in Figure 15. The dissipative coefficient is defined by the following equation:

$$
E=\frac{S_{(\mathrm{ABC}+\mathrm{CDA})}}{S_{(\mathrm{OBE}+\mathrm{ODF})}}
$$

where $S_{(\mathrm{ABC}+\mathrm{CDA})}$ are the areas of the hysteresis loop and $S_{(\mathrm{OBE}+\mathrm{ODF})}$ are the areas of the trilateral.

For specimen 1TB2, high dissipative coefficients in later stages indicate that the rocking mode has a significant hysteretic energy absorption capability. A perfect dissipative effect is due to the cyclic yielding of longitudinal reinforcements with a high ductility capacity and the gradual crushing of toe. The hysteretic strain curve of the gauging point $S 1$ of specimen 1TB2 in large lateral displacements, which is $50 \mathrm{~mm}$ away from the pier bottom, is shown in Figure 16. If assuming the yielding microstrain of reinforcements is 1400 , then the grey area is a plastic region in Figure 16. It is noticed the hysteresis curve shape is similar to that of a metal buckingrestrained brace, which is symmetrical in tensile and compressive behavior after yield. For reinforcements in plastic zone, the compressive yield rather than buckling behavior can provide a large energy dissipation capacity.

Compared with the hysteresis curve of specimen 1TS2, which is shown in Figure 14(d) and which exhibited a typical "bow" shape with a sliding effect, the rocking hysteresis curve 


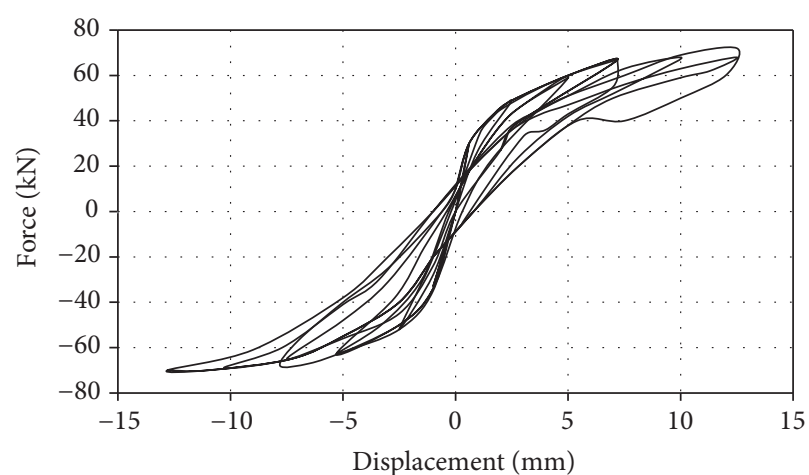

(a)

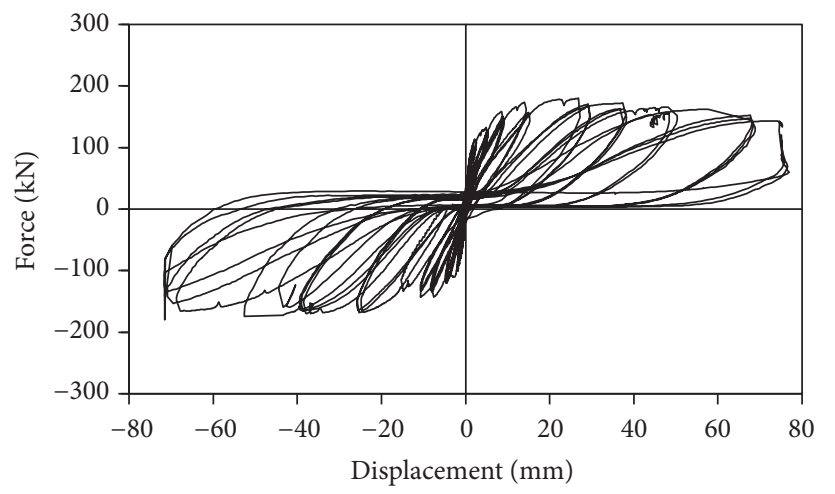

(c)

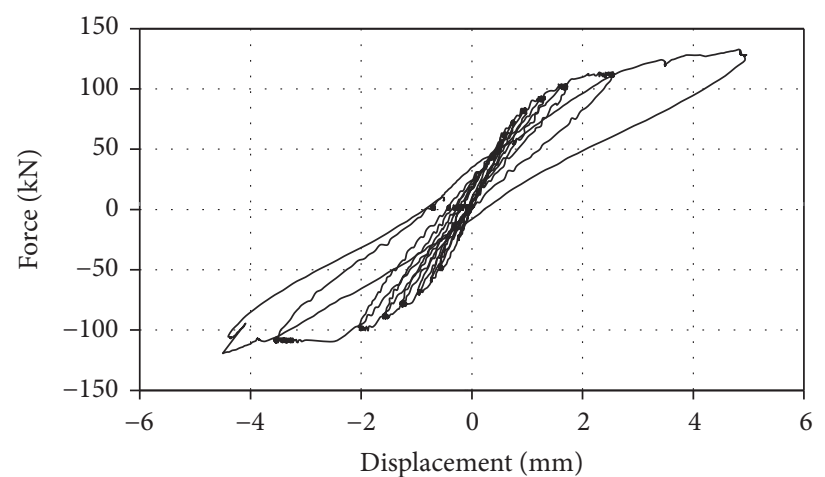

(b)

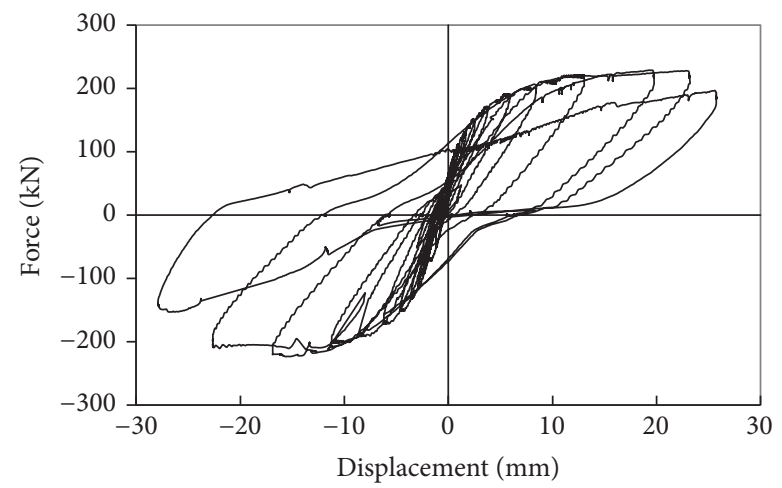

(d)

FIGURE 14: Hysteresis loop according to Anthoine et al. (a) and those of the specimens ((b) is that found in the earlier stage, (c) is the whole curve of specimen 1TB2, and (d) is the curve of specimen 1TS2).

of specimen 1TB2 exhibits a better seismic performance consisting of the self-centering property before steel yield and the high dissipating energy after steel yield. Rocking walls with prestressed technique and with no energy dissipation devices in Figures 2(a)-2(c) display a nonlinear elastic response with essentially no energy dissipation capacity, whereas specimen 1TB2 displays a plastic behavior with self-centering property.

4.6.3. Plastic Hinge Length. Predicated plastic hinge length of the specimen $1 \mathrm{~TB} 2, l_{p}$, is $0.43 \mathrm{~m}$ based on (8). The plastic hinge length $l_{p}$ in (8) is an equivalent length which is used to solve the wall's flexural deflection and plastic rotation capacity. The test value of physical plastic hinge length should be determined by the distribution of strain and cracks, and it was an approximate data in the test. Figure 17 describes the distribution of the maximum strain of longitudinal reinforcements at ultimate curvature, and it indicates that the mechanics assumption of a plastic hinge/rigid plane is appropriate. The maximum length of plastic zone should not exceed $0.67 \mathrm{~m}$ according to a yield strain of $0.14 \%$. If the distribution of cracks was considered, a spacing value of horizontal reinforcements, $0.56 \mathrm{~m}$, may be an appropriate experimental result.

4.6.4. Displacement Performance and Ductility. The backbone curves derived from the envelope curve of hysteresis loops are shown in Figure 18. Backbone curves of specimen
1TB2 and 1TS2 are plotted using a solid curve and a dashed curve in Figure 18, respectively. The corresponding points on the solid curve define specific damage states in test. Note that the story drifts in Figure 18 were calculated by assuming that the story height was equal to $2.8 \mathrm{~m}$.

For specimen 1TB2, rocking behavior governs the maximum strength achieved in the test, and the lateral strength was maintained at high levels of cyclic deformation. As a typical deformation-controlled failure mode, the section of the solid curve from point $b$ to point $d$ is close to $a$ level straight line, the rotation capacity of a plastic hinge is associated with its length, and the corresponding bending moment is the value borne by the plastic hinge. Beyond point e, which is considered as the ultimate displacement point, and when the corresponding story drift is about $2.5 \%$, as shown by the dashed lines in Figure 18, this procedure was not conducted in the test for safety reasons, because the wall would exhibit overturning behavior. Curvatures of a section may be calculated according to the flat section assumption in rocking mode. The estimated yield curvature, $\phi_{y}$, is $0.0029 / \mathrm{mm}$. Assuming that the maximum compressive strain of masonry material equals 0.005 , the result of maximum curvature $\phi_{m}$ is equal to $0.022 / \mathrm{mm}$. Based on (9), the predicted yield displacement at the level of top, $\Delta_{y}$, is $6.3 \mathrm{~mm}$, which has an error of $11.2 \%$ with the test result equal to $7.1 \mathrm{~mm}$. The maximum displacement $\Delta_{p}$ calculated according to (11) is equal to $50.8 \mathrm{~mm}$, which is much small than the test result 


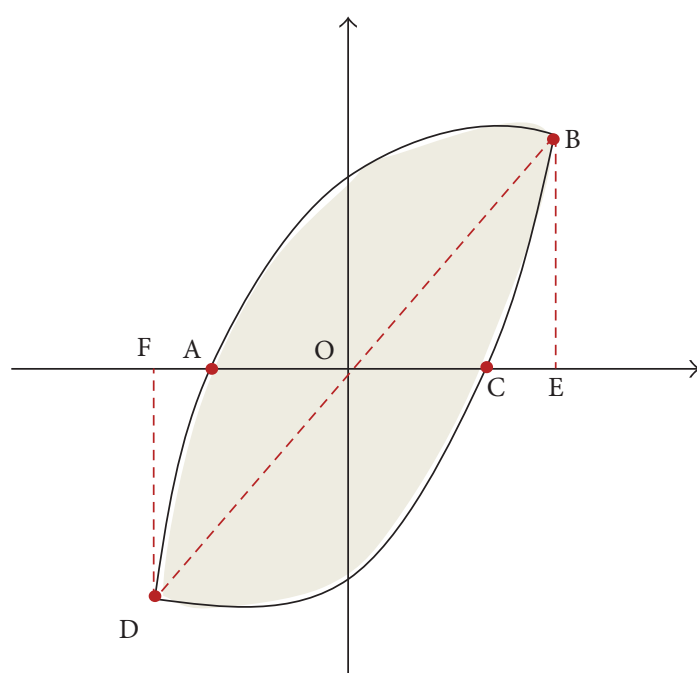

(a)

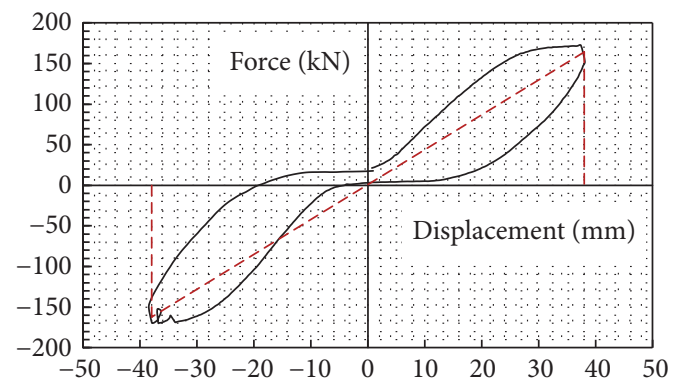

(c) $(E=1.00)$

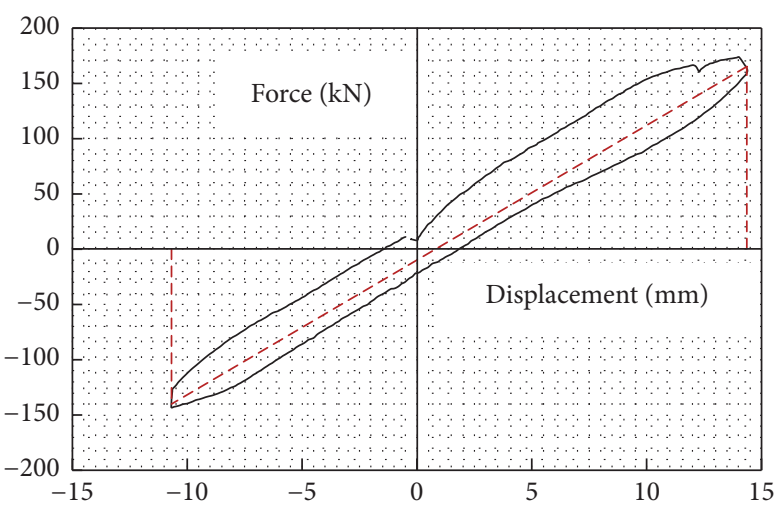

(b) $(E=0.55)$

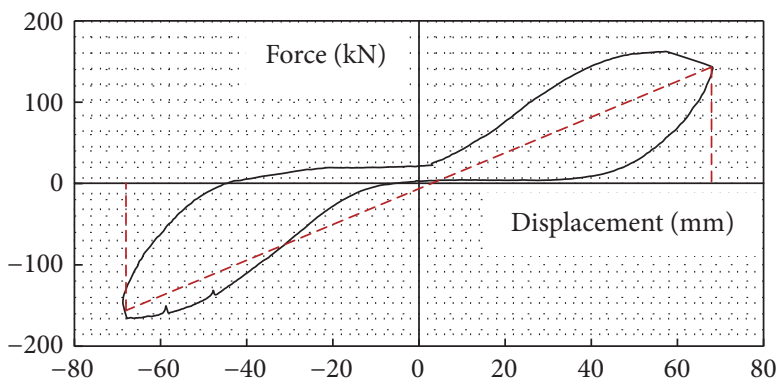

(d) $(E=1.18)$

FIGURE 15: Schematic of dissipative coefficient (a) and the corresponding results in cycle of specimen 1TB2.

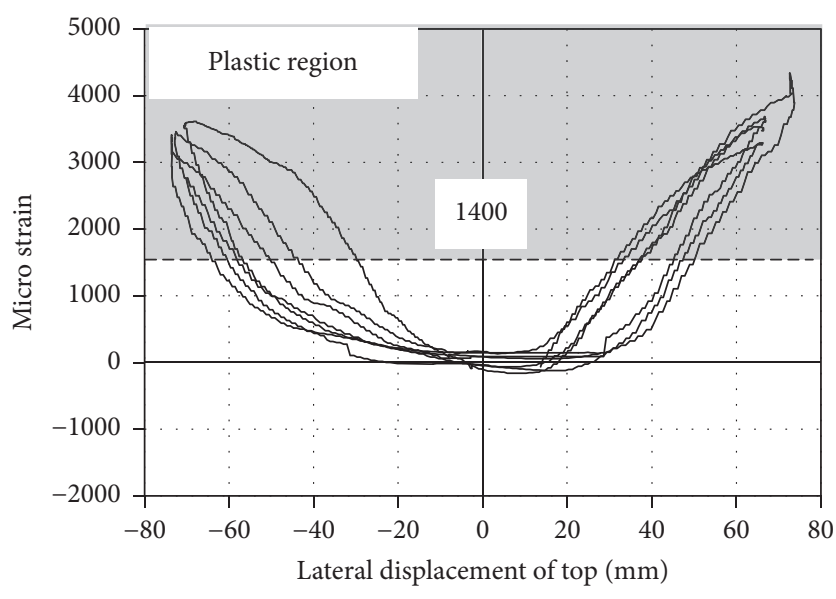

FIGURE 16: Strain hysteresis loop at point S1 in larger lateral displacements.

equal to $69.1 \mathrm{~mm}$. The error in $\Delta_{p}$ is owing to the fact that the experimental ultimate state was determined by $85 \%$ of the peak strength, while the calculating result is based on the maximum compressive strain of masonry, which is the displacement at the crushing point in fact. Small distance between the experimental crushing point and the calculating

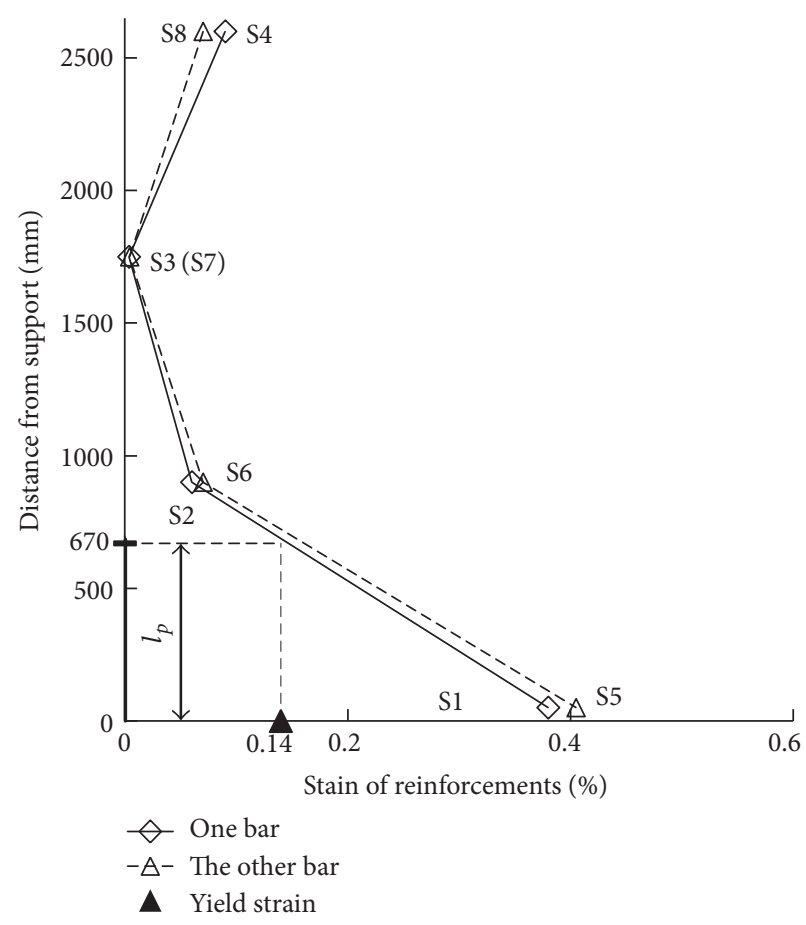

FIGURE 17: Strain distribution of longitudinal reinforcements of specimen $1 \mathrm{~TB} 2$ at maximum curvature. 


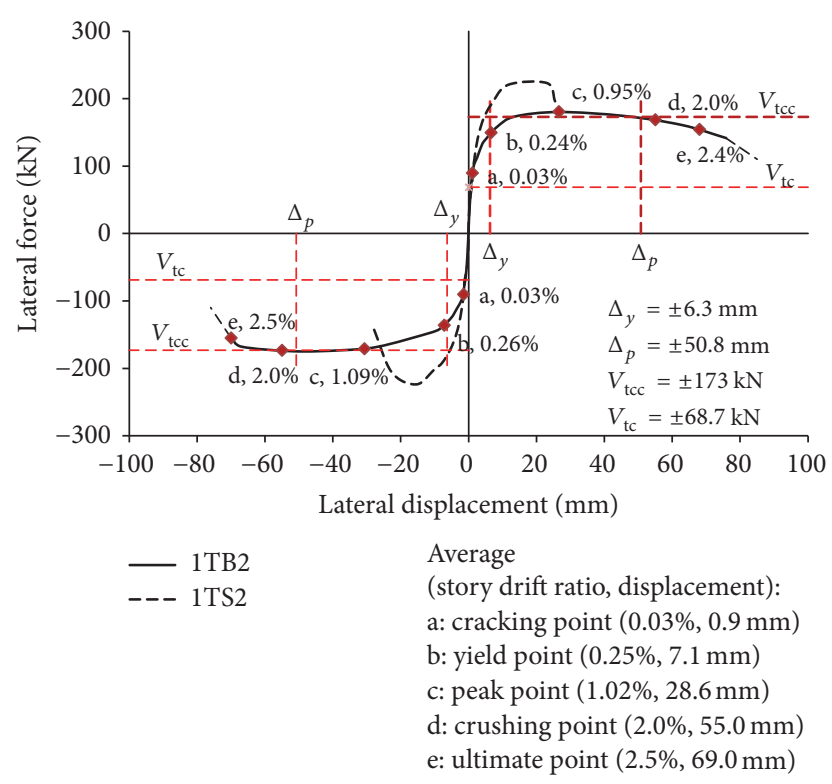

FIGURE 18: Backbone curves of specimens.

ultimate point can be observed in Figure 18. The predicated displacement ductility based on (13) equals 8.0, and the test value is equal to 9.7. Because the displacement ductility is greater than 4, specimen 1TB2 shall be determined as a high ductility component. The predicated width of slots is about $16.5 \mathrm{~mm}$, and the demand in test is about $18.8 \mathrm{~mm}$. Considering the compression capacity of filler material, the width of slots applied in buildings shall be determined by the predicted value multiplied by an amplification factor.

For the backbone curve of specimen 1TS2, a typical brittle mode can be observed; with loading increase, diagonal tension cracks developed, and lateral capacity was rapidly lost. As expected, specimen 1TB2 compared to 1TS2 exhibits a better displacement ductility capacity.

4.6.5. Comparison and Verification of Strengths. The experimental lateral peak strength of specimen 1TB2 and 1TS2 was $182.7 \mathrm{kN}$ and $235.0 \mathrm{kN}$, respectively. After slotting, the lateral peak strength of the specimen decreased by $22.3 \%$ in the test.

As mentioned in Section 4.6.3, for the specimen ITB2, the predicted value of plastic hinge length is considered equal to $0.43 \mathrm{~m}$, and then the parameter, $h_{\text {eff }}$, which is used to predict the lateral strength of the pier should be equal to $1.62 \mathrm{~m}$. The predicted lateral strength $V_{\text {tcc }}$ of specimen 1TB2, which is calculated based on (4), is equal to $173.0 \mathrm{kN}$. $V_{\mathrm{tcc}}$ has a margin of error of $5.3 \%$ with the experimental result. Assuming that specimen 1TB2 did not consist of an SCC, then the predicted lateral strength $V_{\mathrm{tc}}$ is equal to $68.7 \mathrm{kN}$ based on (3). Both of the predicted strengths $V_{\mathrm{tcc}}$ and $V_{\mathrm{tc}}$ are also shown in Figure 18. Since an SCC is at the center of piers, the first flexural cracking strength of piers under rocking behavior should be close to that of piers without an SCC. $V_{\text {tc }}$ is only $14.5 \%$ higher than the experimental cracking strength. After adding an SCC, the predicted strength $V_{\text {tcc }}$ is $151.8 \%$ higher than $V_{\text {tc }}$; this significant increased strength is mainly provided by steel, despite the fact that longitudinal reinforcement ratio is low in the SCC.

\section{Conclusions}

Although both specimens firstly showed the flexural cracks in test, different failure modes ultimately occurred owing to the various aspect ratios. In most cases, boundary limits of slotting piers might be sufficient to avoid shear failure. This slotting strategy could be expected to apply in seismic design of masonry buildings. The following points summarize the conclusions:

(1) A construction strategy of multistory masonry buildings with rocking mode is proposed in the paper. A masonry building is divided to ordinary seismic zone and key seismic zone in the construction. Slots are applied in key seismic zone.

(2) Experimental verification shows that slotting masonry piers with an SCC achieves a change of failure modes from shear to rocking, and the rocking specimen exhibits a stable mechanism with a large deformation.

(3) Rocking earthquake-resistant system for a masonry pier with an SCC consists of self-centering property, high energy dissipation, and high ductility capacity. Although the lateral strength decreased by $22.3 \%$ after slotting, a lateral story drift ratio of approximately $2.5 \%$ and a high displacement ductility of approximately 9.7 are achieved in test.

(4) For the specimen 1TB2, the full hysteretic curve was observed and the high dissipative coefficient was obtained in the later stages. Compared with a rocking URM pier, or a rocking wall with prestressed technique and with no energy dissipation devices, the hysteretic energy absorption capability of a rocking pier with an SCC increases significantly under a large lateral displacement.

(5) Equations proposed in the paper are successful in predicting rocking strengths of piers with an SCC. The test result of rocking displacements has a good agreement with the predicted value according to existing equations.

(6) Test procedure indicated that the initial slotting width of $10 \mathrm{~mm}$ is insufficient for rocking behavior with a large deformation level. The predicated width of slots is about $16.5 \mathrm{~mm}$, which is close to the demanded value of the deformation of the rocking pier in test. The width of slots applied in buildings shall exceeds the predicted value, which helps to reduce the uncertainty in the change of failure mode, and also note that the filler material should be sufficiently soft.

(7) Distribution of horizontal reinforcements has an influence on the propagation of cracks and the plastic hinge length in the rocking failure mode. 


\section{Conflicts of Interest}

The authors declare that they have no conflicts of interest.

\section{Acknowledgments}

This research is supported by the National Science Foundation of China under Grant no. 50978177.

\section{References}

[1] Y. C. Yang, L. Yang, Y. X. Gao et al., "Relation between damage to multi-storey brick buildings and their strength during the TangShan earthquake," Earthquake Engineering and Engineering Vibration, vol. 1, no. 1, pp. 21-35, 1981.

[2] GB 50203-2011, Code for Acceptance of Constructional Quality of Masonry Structures, China Architecture \& Building Press, Beijing, China, 2011.

[3] GB 50011-2010, Code for Seismic Design of Buildings, China Architecture \& Building Press, Beijing, China, 2010.

[4] N. Augenti and F. Parisi, "Learning from construction failures due to the 2009 L'Aquila, Italy, earthquake," Journal of Performance of Constructed Facilities, vol. 24, no. 6, pp. 536-555, 2010.

[5] T. Yi, F. L. Moon, R. T. Leon, and L. F. Kahn, "Lateral load tests on a two-story unreinforced masonry building," Journal of Structural Engineering, vol. 132, no. 5, pp. 643-652, 2006.

[6] J. K. Bothara, R. P. Dhakal, and J. B. Mander, "Seismic performance of an unreinforced masonry building: an experimental investigation," Earthquake Engineering and Structural Dynamics, vol. 39, no. 1, pp. 45-68, 2010.

[7] L. G. Cormack, "The design and construction of the major bridges on the mangaweka rail deviation," Transactions of the Institute of Professional Engineers of New Zealand, vol. 15, no. 1, pp. 6-23, 1998.

[8] D. Ryu, A. C. Wijeyewickrema, M. A. Elgawady, and M. A. K. M. Madurapperuma, "Effects of tendon spacing on in-plane behavior of posttensioned masonry walls," Journal of Structural Engineering, vol. 140, no. 4, Article ID 4013096, 2014.

[9] R. Hassanli, M. A. ElGawady, and J. E. Mills, "Strength and seismic performance factors of posttensioned masonry walls," Journal of Structural Engineering, vol. 141, no. 11, Article ID 04015038, 2015.

[10] J. I. Restrepo and A. Rahman, "Seismic performance of selfcentering structural walls incorporating energy dissipators," Journal of Structural Engineering, vol. 133, no. 11, pp. 1560-1570, 2007.

[11] G. D. Wight, M. J. Kowalsky, and J. M. Ingham, "Shake table testing of posttensioned concrete masonry walls with openings," Journal of Structural Engineering, vol. 133, no. 11, pp. 1551-1559, 2007.

[12] M. A. ElGawady, P. Lestuzzi, and M. Badoux, "Performance of URM walls under in-plane seismic loading," The Masonry Society Journal, no. 23, pp. 85-104, 2005.

[13] J. F. Stanton and S. D. Nakaki, "Design Guidelines for Precast Concrete Structural Systems," PRESSS Report 01/03-09, Dept. of Civil Engineering, University of Washington, 2002.

[14] H. Liu, M. J. Han, C. G. Lan, and X. Z. Yang, "Pseudo-dynamic test and quasi-static test of full-scale model of a two-story brick building retrofitted with prestressed tendons," China Civil Engineering Journal, vol. 49, no. 3, pp. 43-55, 2016.
[15] H. Liu, L. R. Ban, C. G. Lan, T. Wang, and Y. J. Tian, "Quasistatic test of unreinforced brick walls retrofitted with posttensioning tendons," China Journal of Building Structures, vol. 36, no. 8, pp. 142-149, 2015.

[16] R. Ma, L. Jiang, M. He, C. Fang, and F. Liang, "Experimental investigations on masonry structures using external prestressing techniques for improving seismic performance," Engineering Structures, vol. 42, pp. 297-307, 2012.

[17] Council BSS, NEHRP Guidelines for the Seismic Rehabilitation of Buildings, Federal Emergency Management Agency, Washington, DC, USA, FEMA-273 edition, 1997.

[18] Council BSS, Evaluation of earthquake damaged concrete and masonry wall buildings, Federal Emergency Management Agency, Washington, DC, USA, FEMA 306 edition, 1999.

[19] D. C. Rai, "Hysterretic behavior of unreinforced masonry piers strengthened with steel elements," in Proceedings of the Eleventh World Conference on Earthquake Engineering, pp. 501-509, Japan, 1996.

[20] G. Magenes and G. M. Calvi, "In-plane seismic response of brick masonry walls," Earthquake Engineering \& Structural Dynamics, vol. 26, no. 11, pp. 1091-1112, 1997.

[21] A. H. Salmanpour, N. Mojsilovic, and J. Schwartz, "Deformation capacity of unreinforced masonry walls subjected to in-plane loading: a state-of-the-art review," Advanced Structural Engineering, vol. 5, no. 1, article no. 22, 2013.

[22] S. Petry and K. Beyer, "Force-displacement response of inplane-loaded URM walls with a dominating flexural mode," Earthquake Engineering and Structural Dynamics, vol. 44, no. 14, pp. 2551-2573, 2015.

[23] T. Paulay and M. J. N. Priestley, Seismic Design of Reinforced Concrete and Masonry Buildings, John Wiley \& Sons, New York, NY, USA, 1992.

[24] A. Anthoine, G. Magonette, and G. Magenes, "Shear-compression testing and analysis of brick masonry walls," in Proceedings of the 10th European Conference on Earthquake Engineering, pp. $1657-1662,1995$.

[25] G. M. Calvi, G. R. Kingsley, and G. Magenes, "Testing of masonry structures for seismic assessment," Earthquake Spectra, vol. 12, no. 1, pp. 145-162, 1996.

[26] F. Parisi, N. Augenti, A. Balsamo, A. Prota, and G. Manfredi, "Lateral loading tests on a masonry system with and without external reinforcement," in Proceedings of the 14th European Conference on Earthquake Engineering, Ohrid, Macedonia, 2010. 

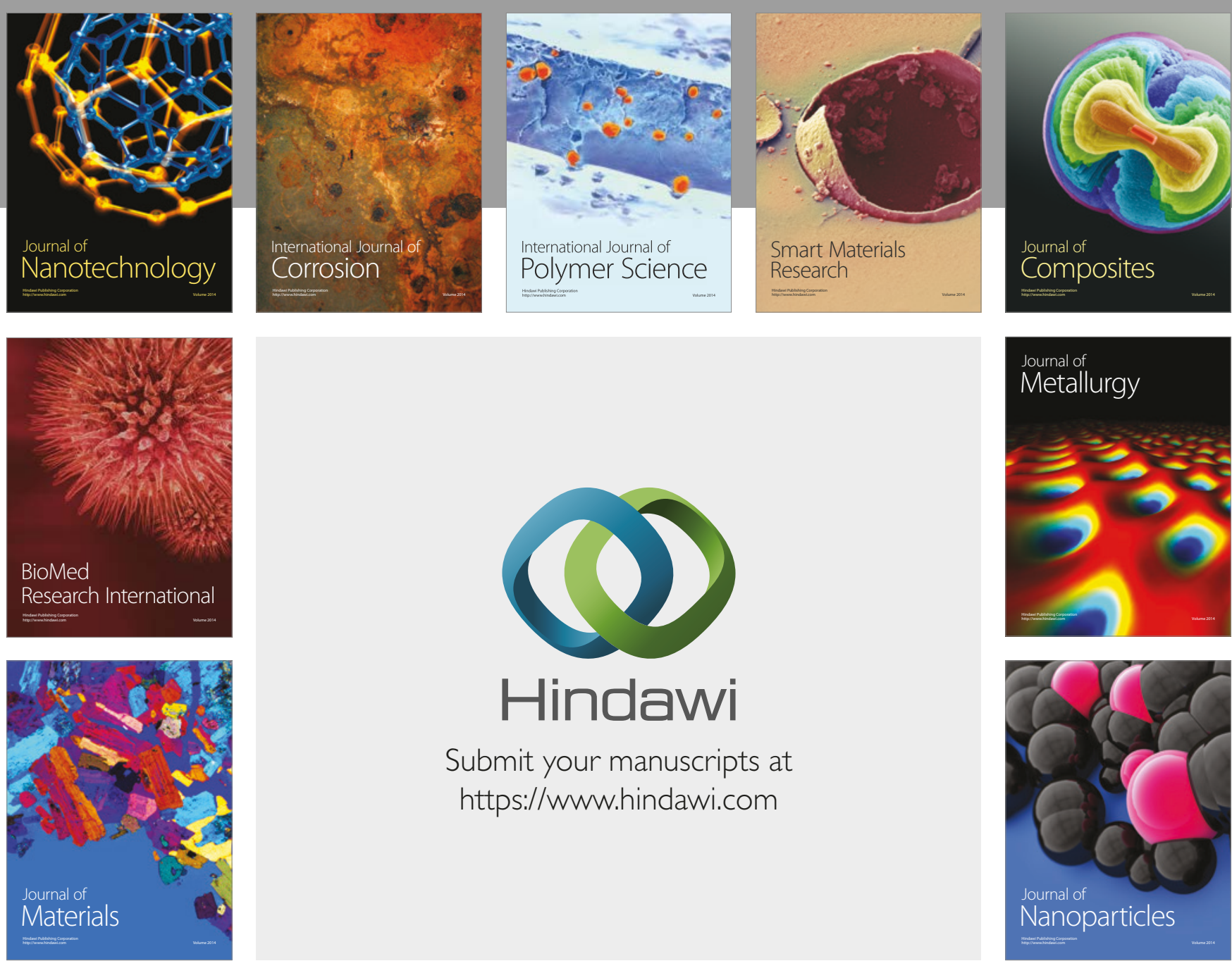

\section{Hindawi}

Submit your manuscripts at

https://www.hindawi.com
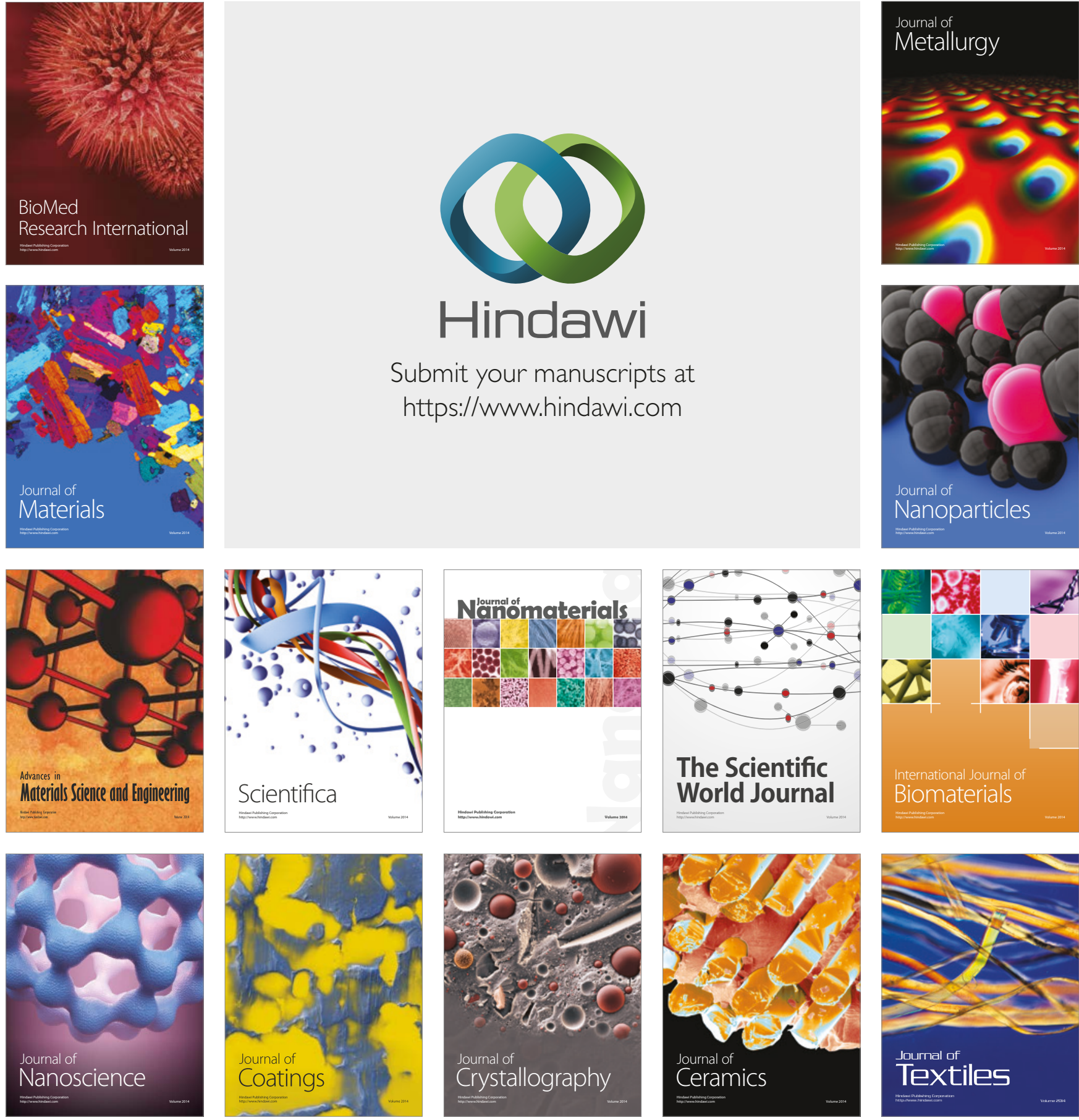

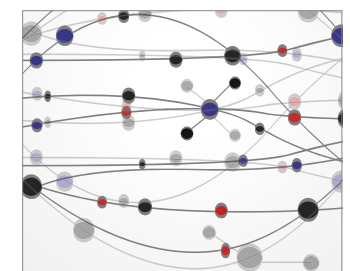

The Scientific World Journal
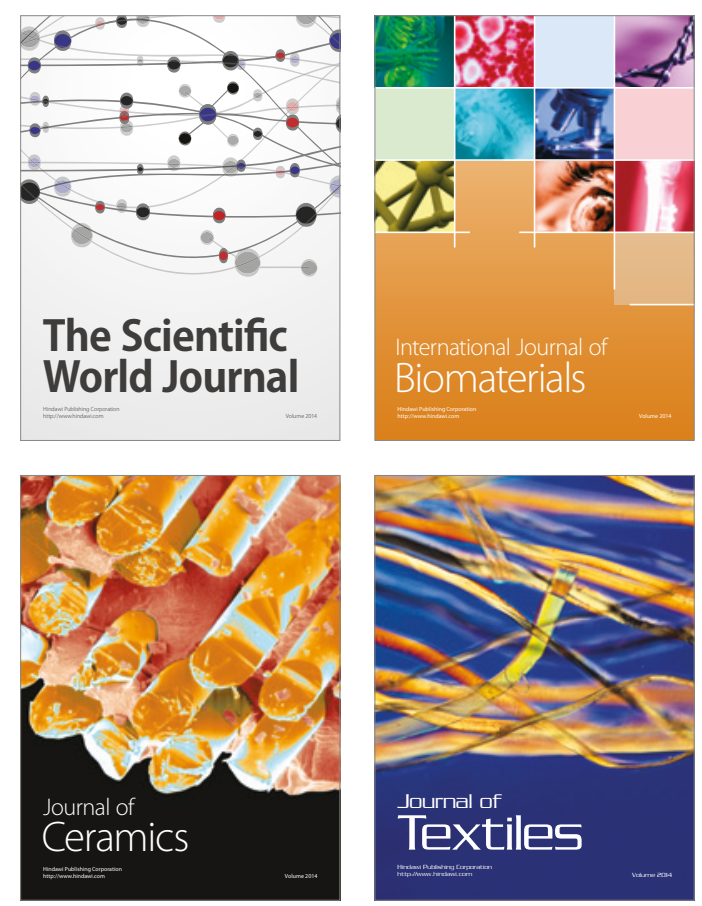